\title{
Benign-appearing Intraspinal Malignant Peripheral Nerve Sheath Tumors: Treatments and Outcomes of 14 Consecutive Patients
}

\author{
Haiyi GONG*, Dan ZHANG*, Da WANG*, Shaohui HE, Xinghai YANG, Haifeng WEl, Jianru XIAO \\ Naval Medical University, Changzheng Hospital, Department of Orthopaedic Oncology, Shanghai, China \\ *Haiyi GONG, Dan ZHANG and Da WANG contributed equally to this work.
}

\section{ABSTRACT}

AIM: To investigate the clinical characteristics and prognostic factors that may influence outcomes of patients undergoing benignappearing intraspinal malignant peripheral nerve sheath tumors (MPNSTs).

MATERIAL and METHODS: This study included a total of 14 consecutive patients who were diagnosed with benign intraspinal tumors firstly and confirmed as intraspinal MPNSTs by pathology. The univariate analyses of various clinical factors were performed to identify variables that could predict prognosis. Endpoints were mortality and local recurrence. The survival rate was estimated using the Kaplan-Meier method, and differences were analyzed by carrying out the log-rank test. In addition, factors with $p$ values of $\leq 0.05$ were considered statistically significant.

RESULTS: Benign-appearing intraspinal MPNSTs showed some different clinical features compared with spinal MPNSTs and intraspinal benign tumors. The present study found that age at diagnosis, Neurofibromatosis type 1 (NF-1) history, tumor sites, malignant grade, Ki-67 and tumor resection method might be factors closely associated with recurrence and survival of intraspinal MPNSTs patients.

CONCLUSION: Benign-appearing intraspinal MPNSTs are relatively rare tumors with a better overall prognosis compared with common spinal MPNSTs. A lot of factors can affect patients' survival and local recurrence. These prognostic factors still require further confirmation with further studies including more patients.

KEYWORDS: Benign appearance, Clinical characteristic, Malignant peripheral nerve sheath tumor, Prognostic factor, Spine, Univariate analysis

ABBREVIATIONS: MPNSTs: Malignant Peripheral Nerve Sheath Tumors, NF-1: Neurofibromatosis type 1, CT: Computed tomography, MRI: Magnetic resonance imaging, WHO: World Health Organization.

\section{INTRODUCTION}

$\mathrm{T}$ The isolated intraspinal tumor tends to be a benign tumor which mostly originates from the branch or sheath of peripheral nerve fibers. However, intraspinal malignant tumor remains rare in the spinal canal without involving surrounding osseous or soft tissues. These tumors may have some special characteristics and patients suffering from them may have a different survival. However, studies concerning the clinical features and outcomes of this kind of benign appearing tumors are rarely reported. Malignant peripheral nerve sheath tumors (MPNSTs) are rare soft-tissue sarcomas originating from Schwann cells or pluripotent cells 
of neural crest origin, accounting for $3 \%-10 \%$ of all soft tissue sarcomas $(5,6,12)$. The incidence of MPNSTs in the general population is $1: 100,000$. Up to $50 \%$ of these tumors occur in patients with neurofibromatosis Type 1 (NF1)(3\%-5\%) $(11,16)$, and $10 \%$ of them have a previous history of radiation therapy $(12,14,15)$. The most common locations for MPNSTs are the trunk, limbs, head and neck (6). During the past several decades, few reports on spinal MPNSTs can be found. Therefore, we present our clinical experience with the features and management of 14 consecutive patients undergoing diagnosed benign intraspinal tumors firstly and confirmed as intraspinal MPNSTs by pathology after surgery, reporting outcomes with relatively long-term follow-up at our center in a 10-year period (2006-2015).

\section{MATERIAL and METHODS}

We collected all patients' data from 2006 to 2015, including the clinical and operative notes, radiographic images, and pathological reports. Every patient's clinical file was discreetly reviewed. A benign-appearing intraspinal tumor was defined as a tumor located only intradural-extramedullary, intramedullary or with partial paravertebral tumor connected through intervertebral foramina without erosion of surrounding bone and tissues. According to the imaging findings [computed tomography $(\mathrm{CT})$ and magnetic resonance imaging (MRI) scans], no aggressive biological characteristic can be observed. The tumor was firstly diagnosed as a benign intraspinal tumor by experience preoperation, and confirmed as a malignant tumor by pathology postoperation. All these patients had regular annual follow-up information until the final follow-up of March 2017. In addition, this study was approved by the hospital ethics committee and informed consent was collected.

Quantitative data are described by median (range) and qualitative data are described as counts and percentages. The univariate analyses of various clinical factors were performed to identify variables that could predict prognosis. Patient factors included age, gender, duration of preoperative symptoms and preoperative Frankel score. Treatment factors were tumor resection method and postoperative adjuvant therapy (radiotherapy or chemotherapy). Tumor factors consisted of tumor site, pathology and the histochemical biomarker Ki-67. Endpoints were mortality and local recurrence. The survival rate was estimated based on the Kaplan-Meier method, and differences were analyzed by conducting the log-rank test. Data were described by Mean \pm Sem $(m)$ and $p$ value. Factors with $p$ values of $\leq 0.05$ were subjected to multivariate analysis for survival rate by multivariate Cox proportional hazards analysis. $p$ values of less than 0.05 were considered statistically significant and all statistical calculations were performed by Predictive Analytics SoftWare (PASW) Statistics, version 22.0 .

\section{- RESULTS}

\section{Patient Information and Clinical Features}

A total of 14 consecutive patients were diagnosed with intraspinal benign tumors by radiology preoperatively but
MPNSTs by pathology postoperatively in the past 10 years, since 2006 (Table I). The gender ratio is $1: 1$ ( 7 female to 7 male). The mean age at diagnosis was 45.6 years (range 23-66 years). All these patients were firstly admitted to our center for neurological syndrome and none of them had a previous malignant tumor history. Three of these patients had an NF-1 history (Patient \#2, \#9 and \#13). None of them had a radiotherapy history. There was no obvious preference to different spine region for intra-spinal MPNSTs (3 in cervical spine, 1 in cervicothoracic spine, 2 in thoracic spine, 2 in thoracolumbar spine and 6 in lumbar spine). The intraspinal tumors commonly presented as an extradural, intradural extramedullary, or rarely intramedullary neoplasms, which did not involve the vertebrae. In our cases, 2 of these 14 patients were intramedullary tumors (Patient \#10 and \#11), 3 of them were intradural extramedullary tumors without intact pseudocapsules (Patient \#5, \#8 and \#9), and 8 of them were intradural extramedullary tumors with intact pseudocapsules. The remaining one was an extradural tumor (Patient \#2).

Clinically, pain and neurological deficit were the most common symptoms. Although pain was usually the first symptom and the most frequently reported, weakness of limbs was the main complaint when they came for medical intervention. All these 14 patients had at least one kind of neurological deficit, including muscle weakness, numbness, constipation, paresthesia, paraplegia, etc. With an average of approximately 14.3 months, the duration of the preoperative symptoms ranged from 0.5 to 48 months.

\section{Histological Findings}

All the MPNST diagnoses were confirmed by at least two senior pathologists and all MPNSTs can be roughly divided into two groups including "lower malignancy group" and "higher malignancy group" based on tumor cells growth characteristics, invasive extension, intactness of tumor pseudocapsule, and histochemistry.

\section{Management}

Operation was the first choice for patient with neurological deficit caused by intraspinal tumor compression. All these patients underwent surgery on the basis of posterior approach. Relevant vertebral lamina was removed. Pedicle screw-rod system was used to reconstruct the stability of spine. Because all these cases were primarily not diagnosed as malignant tumor, none of the patients had preoperative adjuvant therapies. Two of them went through postoperative radiotherapy due to incomplete excision of the tumor (Patient $\# 9$ and \#10). None of the other patients received any other therapy except regularly follow-up.

\section{Follow-up and Outcome}

The average follow-up duration of the patients in this study was 47.7 months (ranging 2-113 months). The average diseasefree duration was 45.6 months (range 2-113 months). A total of five patients died during follow-up (Patient \#2, \#5, \#9, \#10, \#13). Eighteen operations had been conducted for these 14 patients. Three of them went through over one operation at our institution (Patient \#2, \#10 and \#14). 
Table I: Patient Information, Clinical Features, Histological Findings, Management, Follow-Up and Outcome

\begin{tabular}{|c|c|c|c|c|c|c|c|c|c|c|c|c|c|}
\hline Patient & ender & $\begin{array}{c}\text { Age } \\
\text { (Years) }\end{array}$ & $\begin{array}{c}\text { PSD } \\
\text { (Months) }\end{array}$ & PFS & Tumor Location & Ki-67 & grade & Resection & NF1 & $\begin{array}{c}\text { FDT } \\
\text { (Months) }\end{array}$ & Recurrence & $\begin{array}{l}\text { Survival } \\
\text { (Months) }\end{array}$ & $\begin{array}{l}\text { Out- } \\
\text { come }\end{array}$ \\
\hline $1 \#$ & $\mathrm{~F}$ & 50 & 48 & $\mathrm{D}$ & $\begin{array}{c}\text { intact } \\
\text { pseudocapsules }\end{array}$ & $5 \%$ & low & en bloc & $\mathrm{N}$ & 113 & $\mathrm{~N}$ & 113 & Alive \\
\hline 2\# & $\mathrm{F}$ & 49 & 5 & C & extradural & $20 \%$ & high & piecemeal & $\mathrm{Y}$ & 5 & $Y$ & 9 & Dead \\
\hline 3\# & $\mathrm{F}$ & 35 & 5 & $\mathrm{D}$ & $\begin{array}{c}\text { intact } \\
\text { pseudocapsules }\end{array}$ & $20 \%$ & low & en bloc & $\mathrm{N}$ & 92 & $\mathrm{~N}$ & 92 & Alive \\
\hline $4 \#$ & M & 55 & 12 & $\mathrm{D}$ & $\begin{array}{c}\text { intact } \\
\text { pseudocapsules }\end{array}$ & $10 \%$ & low & en bloc & $\mathrm{N}$ & 66 & N & 66 & Alive \\
\hline $5 \#$ & M & 43 & 36 & C & $\begin{array}{c}\text { w/o intact } \\
\text { pseudocapsules }\end{array}$ & $20 \%$ & high & piecemeal & $\mathrm{N}$ & 2 & N & 2 & Dead \\
\hline $6 \#$ & $\mathrm{~F}$ & 51 & 12 & $E$ & $\begin{array}{c}\text { intact } \\
\text { pseudocapsules }\end{array}$ & $1 \%$ & low & piecemeal & $\mathrm{N}$ & 55 & N & 55 & Alive \\
\hline $7 \#$ & $\mathrm{~F}$ & 46 & 9 & C & $\begin{array}{c}\text { intact } \\
\text { pseudocapsules }\end{array}$ & $15 \%$ & low & en bloc & $N$ & 53 & $\mathrm{~N}$ & 53 & Alive \\
\hline 8\# & M & 66 & 3 & $\mathrm{D}$ & $\begin{array}{c}\text { w/o intact } \\
\text { pseudocapsules }\end{array}$ & $10 \%$ & low & piecemeal & $\mathrm{N}$ & 41 & N & 41 & Alive \\
\hline 9\# & M & 23 & 2 & $\mathrm{D}$ & $\begin{array}{c}\text { w/o intact } \\
\text { pseudocapsules }\end{array}$ & $20 \%$ & high & piecemeal & $\mathrm{Y}$ & 30 & Y & 32 & Dead \\
\hline $10 \#$ & $\mathrm{M}$ & 47 & 24 & $\mathrm{D}$ & intramedullary & $5 \%$ & low & debulk & $\mathrm{N}$ & 14 & $Y$ & 24 & Dead \\
\hline 11\# & $M$ & 32 & 0.5 & $\mathrm{D}$ & intramedullary & $10 \%$ & low & debulk & $\mathrm{N}$ & 30 & $\mathrm{~N}$ & 30 & Alive \\
\hline $12 \#$ & M & 55 & 2 & $\mathrm{D}$ & $\begin{array}{c}\text { intact } \\
\text { pseudocapsules }\end{array}$ & $2 \%$ & low & en bloc & $\mathrm{N}$ & 27 & N & 27 & Alive \\
\hline $13 \#$ & $\mathrm{~F}$ & 30 & 6 & $E$ & $\begin{array}{c}\text { intact } \\
\text { pseudocapsules }\end{array}$ & $15 \%$ & low & piecemeal & $\mathrm{Y}$ & 26 & Y & 37 & Dead \\
\hline $14 \#$ & $\mathrm{~F}$ & 56 & 36 & $\mathrm{D}$ & $\begin{array}{c}\text { intact } \\
\text { pseudocapsules }\end{array}$ & $5 \%$ & low & en bloc & $\mathrm{N}$ & 85 & Y & 87 & Alive \\
\hline
\end{tabular}

PSD: Preoperative syndrome duration, FDT: Free disease duration, PFS: Preoperative Frankel score.

Table II: Analysis of the Prognostic Factors Affecting Recurrence and Survival Time

\begin{tabular}{|c|c|c|c|c|c|}
\hline \multirow[b]{2}{*}{ Patient factors } & & \multicolumn{2}{|c|}{ Free disease duration (Months) } & \multicolumn{2}{|l|}{ Survival (Months) } \\
\hline & & Mean $\pm \operatorname{Sem}(m)$ & p value & Mean \pm Sem $(m)$ & $\mathrm{p}$ value \\
\hline Age ( $<50$ vs. $\geq 50$ years) & $8 / 6$ & $64.5 \pm 12.7$ Vs. $31.5 \pm 10.4$ & 0.117 & $64.8 \pm 12.8$ Vs. $34.9 \pm 9.9$ & 0.020 \\
\hline Gender (Male vs. Female) & $7 / 7$ & $30.0 \pm 7.7$ Vs. $61.3 \pm 14.4$ & 0.889 & $31.7 \pm 7.3$ Vs. $63.7 \pm 13.5$ & 0.375 \\
\hline DPS (<12 vs. $\geq 12)$ & $8 / 6$ & $38.0 \pm 9.1$ Vs. $55.8 \pm 17.2$ & 0.799 & $40.1 \pm 8.6$ Vs. $57.8 \pm 16.6$ & 0.875 \\
\hline PFS ( $\leq$ C vs. $\geq D)$ & $3 / 11$ & $20.0 \pm 16.5$ Vs. $52.6 \pm 9.7$ & 0.368 & $21.3 \pm 16.0$ Vs. $54.9 \pm 9.2$ & 0.086 \\
\hline $\begin{array}{l}\text { NF-1 history (NF-1 history vs. no } \\
\text { NF-1 history) }\end{array}$ & $3 / 11$ & $20.3 \pm 7.8$ Vs. $52.5 \pm 10.4$ & 0.002 & $26.0 \pm 8.6$ Vs. $53.6 \pm 10.1$ & 0.020 \\
\hline \multicolumn{6}{|l|}{ Treatment factors } \\
\hline $\begin{array}{l}\text { TRM (En bloc vs. subtotal or } \\
\text { piecemeal total) }\end{array}$ & $6 / 8$ & $72.7 \pm 12.5$ Vs. $25.4 \pm 6.3$ & 0.039 & $73.0 \pm 12.7$ Vs. $28.6 \pm 6.0$ & 0.020 \\
\hline \multicolumn{6}{|l|}{ Tumor factors } \\
\hline $\begin{array}{l}\text { tumor site (extradural or intramedullary } \\
\text { vs. intradural extramedullary) }\end{array}$ & $6 / 8$ & $20.3 \pm 6.4$ Vs. $64.6 \pm 10.9$ & 0.074 & $23.0 \pm 6.0$ Vs. $66.3 \pm 10.3$ & 0.012 \\
\hline pathology (lower grade vs. higher grade) & $11 / 3$ & $54.7 \pm 9.5$ Vs. $12.3 \pm 8.9$ & 0.012 & $56.8 \pm 8.9$ Vs. $14.3 \pm 9.1$ & 0.000 \\
\hline \multicolumn{6}{|l|}{ Histochemical biomakers } \\
\hline Ki-67 (<20\% vs. $\geq 20 \%)$ & $10 / 4$ & $94.4 \pm 11.8$ Vs. $32.3 \pm 18.1$ & 0.037 & $94.3 \pm 11.7$ Vs. $33.8 \pm 17.7$ & 0.028 \\
\hline
\end{tabular}

DPS: Duration of preoperative symptoms, PFS: Preoperative Frankel score, TRM: Tumor resection method. 


\section{Univariate Analysis of Prognostic Factors}

Table II shows the univariate analysis of the prognostic factors influencing recurrence and survival time. The 5-year survival rate was $61 \%$. According to statistical analysis, patients older than 50 years at diagnoses had a better survival and longer disease-free duration than those who were younger than 50 years (Figure 1A). There is no statistical difference between male and female on total survival and recurrence. Whether preoperative symptom duration was longer than 12 months or did not affect patients' total survival and recurrence. Additionally, there was also no statistical difference on survival and recurrence between patients with a preoperative Frankel score lower than $\mathrm{C}$ and those who had a score higher than D. There were 3 patients who had a NF-1 history. Based on statistical analysis, patients who had a NF-1 history had a worse prognosis compared with those who did not. The tumor resection method was usually the most relevant factor of patients' total survival and recurrence according to previous studies on spinal tumor (Figure 1B). In our study, patients who went through total tumor resections showed a favorable outcome on total survival and recurrence in comparison with those who only got piecemeal resection or even palliative resection. Tumors located intradural extramedullary with intact pseudocapsule had a significant better survival than others. Patients suffered from tumors classified into higher malignancy had an obvious worse prognosis (Figure 1C). Ki67 expression higher than $20 \%$ or not seemed do not affect patients' outcome (Figure 1D).

\section{Multivariate Analysis of Prognostic Factors}

Univariate analysis indicated that the potential prognostic factors with survival were age $(<50$ years $/ \geq 50$ years), NF-1 history (Yes/No), tumor resection method (En-bloc resection/ subtotal or piecemeal total resection), tumor site (extradural or intramedullary/intradural extramedullary), pathology (lower grade vs higher grade) and Ki-67 expression (<20\% vs $\geq 20 \%$ ). They were submitted to the multivariate Cox regression model for analyzing overall survival. None of them was an independent prognostic factor for survival. Then, we submitted NF-1
(A)
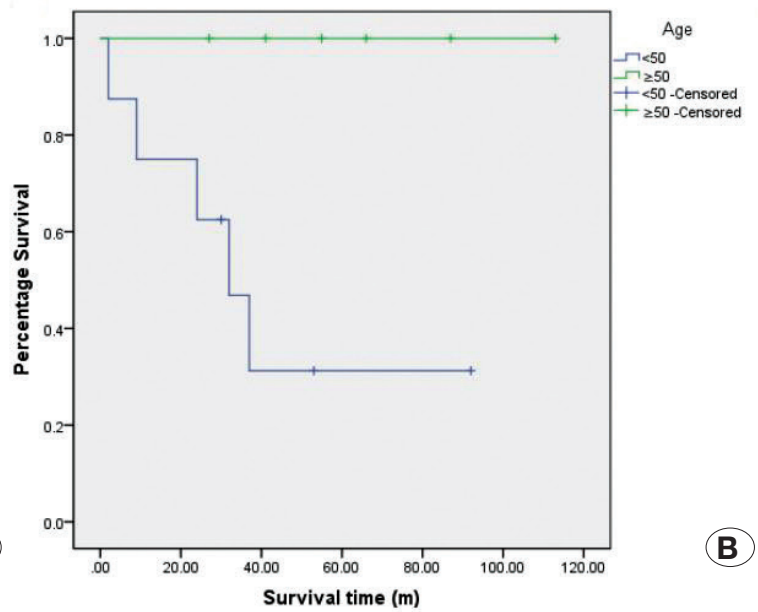

(B)

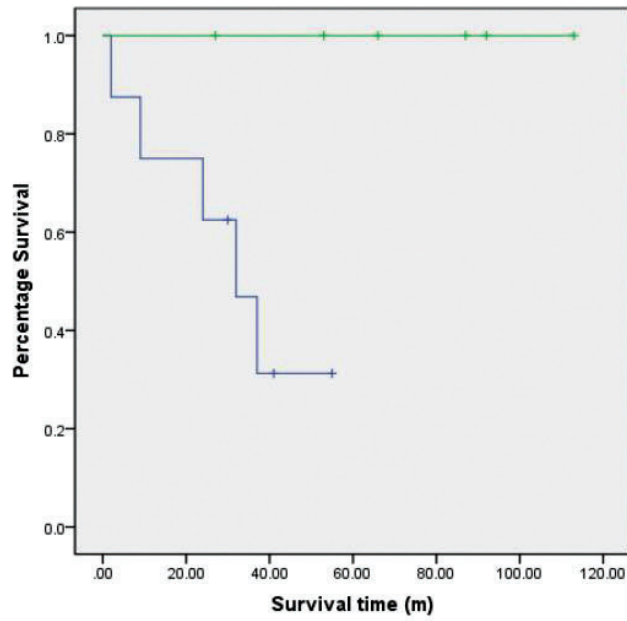

Resection method subtotal or piecemeal total en bloc resection - subtotal or piecemeal total
resection-Censored en bloc resection -
censored
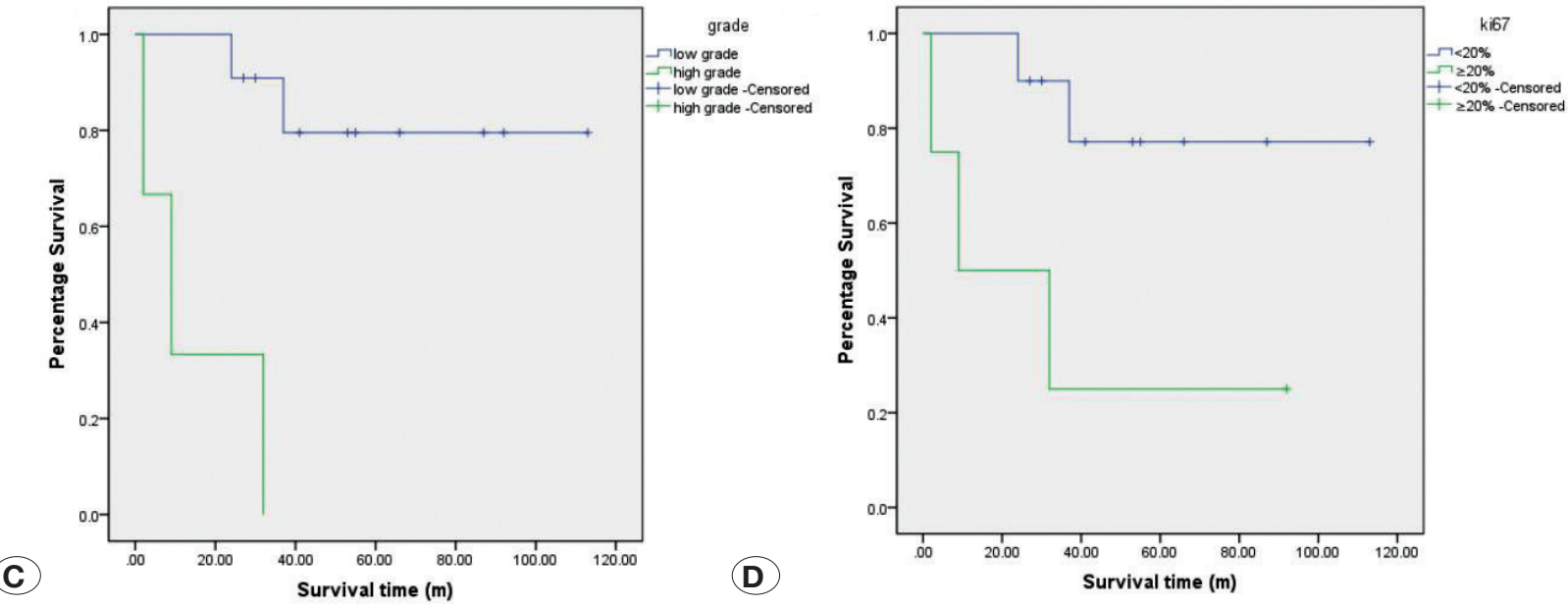

Figure 1: A) Kaplan-Meier curves of survival for age. B) Kaplan-Meier curves of survival for resection method. C) Kaplan-Meier curves of survival for tumor grade. D) Kaplan-Meier curves of survival for Ki-67. 
history (Yes/No), Tumor resection method (En-bloc resection/ subtotal or piecemeal total resection), pathology (lower grade vs. higher grade) and $\mathrm{Ki}-67$ expression ( $<20 \%$ vs. $\geq 20 \%)$ to the multivariate Cox regression model for analysis of free disease duration. However, none of these four candidates was an independent prognostic factor for local recurrence.

\section{DISCUSSION}

MPNSTs are relatively rare soft-tissue sarcomas. The World Health Organization (WHO) coined the term "malignant peripheral nerve sheath tumor" to replace previous heterogeneous and sometimes misleading terminology, such as "malignant schwannoma", "malignant neurilemmoma", "neurogenic sarcoma", and "neurofibrosarcoma" (10). The most common locations for MPNSTs include the trunk, limbs, and head and neck (6). Spinal MPNSTs has been rarely reported. Although an increasingly number of studies focused on this topic in recent years, more related studies on this disease still needs to be enlarged $(5,18,19)$. As an even rarer subtype intraspinal benign appearing MPNSTs were seldom reported, and this study presented 14 consecutive intraspinal MPNSTs patients who were diagnosed as benign tumors first at our center with their detailed clinical files. We studied their clinical characteristics and discussed the possible relative prognostic factors.

Local recurrence and death are not uncommon in spinal MPNST. The reported recurrence rate is $29-53 \%(3,18,20)$, and the 5 -year survival rate is $30-50 \%$ (9). Our results showed that intraspinal benign appearing MPNSTs patients seemed to have a better prognosis than that of common spinal MPNSTs patients $(18,19)$. This is reasonable because intraspinal benignappearing MPNSTs were seen in the spinal canal usually with intact pseudocapsule while vertebrae were not involved. It demonstrated that these tumors were less malignant and aggressive biologically. Therefore, it was easier for surgeons to completely remove the tumor.

Through conducting univariate analysis of prognostic factors, we found that age, NF-1 history, tumor resection method (tumor margin), pathology, tumor site and Ki-67 expression were prognostic factors that might predict the survival and recurrence of patients undergoing intraspinal benign appearing MPNSTs. Compared with those who were older than 50 years, patients younger than 50 at diagnosis had a shorter life span. This phenomenon may be explained by the hypothesis that age at diagnosis is related to tumor malignancy. However, this hypothesis needs to be confirmed by further study. According to a recent meta-analysis with more than 1800 MPNST patients, as many as $50 \%$ of these tumors occur in patients with neurofibromatosis Type 1 (NF1) (3\%-5\%)(12). In addition, the study also showed that MPNSTs arising from NF1 and non-NF1 patients were not different per se. Consequently, it could be suggested that the choice of treatment for MPNST should be independent of NF1 status. However, in our case, only 3 patients out of 14 had a NF-1 history. All these three patients died during follow-up, accounting for $60 \%$ of all dead patients. Through carrying out a log-rank test, there existed significant statistical difference between these two groups. Therefore, even the NF-1 history did not affect the whole MPNST patients' survival, which was possibly tumor malignancy still associated with NF-1 history for benign-appearing intraspinal MPNSTs. Nevertheless, there are too few patients to draw this conclusion. In this study, we had two patients who went through radiotherapies after surgery. Based on the patients' clinical files, it could be found that they got severe delayed radiation-induced myelopathy which significantly affected their life spans and nerve function. As a result, whether postoperative radiotherapy was beneficial for patients with an intraspinal tumor that was incompletely resected was still controversial $(2,17)$. Tumor resection method (tumor margin) was a universally acknowledged prognostic factor for almost all resectable malignant tumors $(1,4,13)$. In our study, most of the benign- appearing intraspinal MPNSTs were intradural extramedullary tumors (accounting for $78.6 \%)$. Those patients with intradural extramedullary tumors undergoing intact pseudocapsule had a significantly better prognosis. For intramedullary tumors and tumors without intact pseudocapsule, there was no obviously clear margin for resection. In terms of extradural tumors, the tumor sometimes may grow out of the intervertebral foramen with a large paravertebral neoplasm. All these contributed to total resection of the tumor being a harder task. Based on statistical study, the Pearson correlation coefficient of tumor sites and tumor resection method is 0.75 , indicating that tumor sites can significantly influence the resection method of intraspinal MPNSTs. Compared with higher malignant MPNSTs, patients with lower malignant MPNSTs had a longer survival and freedisease duration. The Ki-67 protein (also known as MKI67) is a cellular marker for proliferation $(7,8)$. It is strictly associated with cell proliferation. In our cases, patients with tumor $\mathrm{Ki}$ 67 expression higher than $20 \%$ had a worse survival but not recurrence. The histochemical biomarker, Ki-67, was a factor, showing tight association with tumor malignancy. It suggested that intraspinal MPNSTs with a Ki-67 expression higher than $20 \%$ could be classified into "higher malignant tumors" with a worse prognosis. In our another study concerning spinal MPNSTs, we had found that patients with S-100 protein negative had a higher recurrence rate and a lower survival rate (18). However, this study only involved one patient who had a negative $\mathrm{S}-100$. This finding demonstrated again that benignappearing intraspinal MPNSTs were less malignant compared with normal MPNSTs which had a worse overall survival, higher recurrence rate and higher distant metastasis risk (20). However, when all the possible prognostic factors were submitted to multivariate Cox regression model for making the analysis, none of these factors was an independent factor with survival and local recurrence.

\section{CONCLUSION}

Benign-appearing intraspinal MPNSTs are relatively rare tumors with a better overall prognosis compared with common spinal MPNSTs. Intraspinal MPNSTs involve a lot of different characteristics and relevant outcomes. Regarding all the intraspinal tumors regardless of benign or malignant, total tumor resection remains the first choice of treatment. When a MPNST is confirmed according to postoperative pathology, 
rigorous follow-up should be conducted in case of recurrence. Radiotherapy is not recommended due to the possibility of delayed radiation-induced myelopathy. Age at diagnosis, NF-1 history, tumor site, malignant grade and tumor resection method might be factors closely associated with intraspinal MPNSTs patients' recurrence rate and survival, requiring the conformation of high-quality studies.

\section{ACKNOWLEDGEMENT}

The authors thank Professor Jianru XIAO for great supports to this study and conscientious guidance. The authors also thank all the colleagues for their kind help.

\section{- REFERENCES}

1. Ailon T, Torabi R, Fisher CG, Rhines LD, Clarke MJ, Bettegowda C, Boriani S, Yamada YJ, Kawahara N, Varga PP, Shin JH, Saghal A, Gokaslan ZL: Management of locally recurrent chordoma of the mobile spine and sacrum: A systematic review. Spine 41 Suppl 20:S193-S198, 2016

2. Ali HS, Endo T, Endo H, Murakami K, Tominaga T: Intraspinal dissemination of intracranial hemangiopericytoma: Case report and literature review. Surg Neurol Int 7:S1016-S1020, 2016

3. Anghileri M, Miceli R, Fiore M, Mariani L, Ferrari A, Mussi C, Lozza L, Collini P, Olmi P, Casali PG, Pilotti S, Gronchi A: Malignant peripheral nerve sheath tumors: Prognostic factors and survival in a series of patients treated at a single institution. Cancer 107:1065-1074, 2006

4. Charest-Morin R, Fisher CG, Varga PP, Gokaslan ZL, Rhines LD, Reynolds JJ, Dekutoski MB, Quraishi NA, Bilsky MH, Fehlings MG, Chou D, Germscheid NM, Luzzati A, Boriani S, Tumor AOKF: En bloc resection versus intralesional surgery in the treatment of giant cell tumor of the spine. Spine 42(18):1383-1390, 2017

5. Chou D, Bilsky MH, Luzzati A, Fisher CG, Gokaslan ZL, Rhines LD, Dekutoski MB, Fehlings MG, Ghag R, Varga P, Boriani S, Germscheid NM, Reynolds JJ, Tumor AOKF: Malignant peripheral nerve sheath tumors of the spine: Results of surgical management from a multicenter study. J Neurosurg Spine 26:291-298, 2017

6. Ducatman BS, Scheithauer BW, Piepgras DG, Reiman HM, Ilstrup DM: Malignant peripheral nerve sheath tumors. A clinicopathologic study of 120 cases. Cancer 57:2006-2021, 1986

7. Gerdes J, Lemke H, Baisch H, Wacker HH, Schwab U, Stein $\mathrm{H}$ : Cell cycle analysis of a cell proliferation-associated human nuclear antigen defined by the monoclonal antibody Ki-67. J Immunol 133:1710-1715, 1984
8. Gerdes J, Pileri S, Bartels H, Stein H: Proliferation marker Ki-67: Correlation with histological diagnosis, neoplasm grading and clinical course. Verhandlungen der Deutschen Gesellschaft fur Pathologie 70:152-158, 1986 (In German)

9. Grobmyer SR, Reith JD, Shahlaee A, Bush $\mathrm{CH}$, Hochwald SN: Malignant peripheral nerve sheath tumor: Molecular pathogenesis and current management considerations. J Surg Oncol 97:340-349, 2008

10. Gupta G, Maniker A: Malignant peripheral nerve sheath tumors. Neurosurg Focus 22:E12, 2007

11. Hwang IK, Hahn SM, Kim HS, Kim SK, Kim HS, Shin KH, Suh CO, Lyu CJ, Han JW: Outcomes of treatment for malignant peripheral nerve sheath tumors: Different clinical features associated with neurofibromatosis type 1. Cancer Res Treat 49(3):717-726, 2017

12. Kolberg M, Holand M, Agesen TH, Brekke HR, Liestol K, Hall KS, Mertens F, Picci P, Smeland S, Lothe RA: Survival metaanalyses for $>1800$ malignant peripheral nerve sheath tumor patients with and without neurofibromatosis type 1. Neuro Oncol 15:135-147, 2013

13. Lador R, Gasbarrini A, Gambarotti M, Bandiera S, Ghermandi R, Boriani S: Surgeon's perception of margins in spinal en bloc resection surgeries: How reliable is it? Eur Spine J 2017 (Epub Ahead of Print)

14. Maegawa T, Hirasawa M, Sasahara A, Tani S, Hagiwara S, Koseki H, Yoshimura C, Takahashi Y, Kikuchi A, Kasuya H: Radiation-induced malignant peripheral nerve sheath tumor of the high cervical spine. No Shinkei Geka 44:691-698, 2016 (In Japanese)

15. Simmermacher S, Vordermark D, Kegel T, Strauss C: Malignization of vestibular schwannoma 13 years after radiation therapy. HNO 65 Suppl 2:153-157, 2017 (In German)

16. Staedtke V, Bai RY, Blakeley JO: Cancer of the peripheral nerve in neurofibromatosis type 1. Neurotherapeutics 14(2):298306, 2017

17. Stubblefield MD, Ibanez K, Riedel ER, Barzilai O, Laufer I, Lis $\mathrm{E}$, Yamada $\mathrm{Y}$, Bilsky $\mathrm{MH}$ : Peripheral nervous system injury after high-dose single-fraction image-guided stereotactic radiosurgery for spine tumors. Neurosurg Focus 42:E12, 2017

18. Wang T, Yin H, Han S, Yang X, Wang J, Huang Q, Yan W, Zhou $\mathrm{W}$, Xiao J: Malignant peripheral nerve sheath tumor (MPNST) in the spine: A retrospective analysis of clinical and molecular prognostic factors. J Neurooncol 122:349-355, 2015

19. Zhu B, Liu X, Liu Z, Yang S, Liao HI, Jiang L, Wei F: Malignant peripheral nerve sheath tumours of the spine: Clinical manifestations, classification, treatment, and prognostic factors. Eur Spine J 21:897-904, 2012

20. Zou C, Smith KD, Liu J, Lahat G, Myers S, Wang WL, Zhang W, McCutcheon IE, Slopis JM, Lazar AJ, Pollock RE, Lev D: Clinical, pathological, and molecular variables predictive of malignant peripheral nerve sheath tumor outcome. Ann Surg 249:1014-1022, 2009 